\title{
Review and Hypothesis about Gout
}

\author{
Carlos Alberto Paterno Marchioli* \\ Department of Internal Medicine, Italy
}

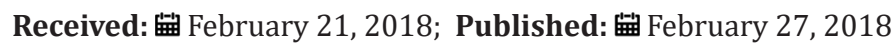

*Corresponding author: Carlos Alberto Paterno Marchioli, Department of Internal Medicine, Italy

\section{Introduction}

The first identification about gout as clinical entity was made by the Egyptians in the year 2640 b.C. (Schwartz 2006). For many centuries it was not unveil the mystery of the origin of the illness. Gout is the unique pathology that belongs to the human race. When uric acid is deposited in the articulate tissue produce an intense inflammation, basic element in the development of gout. Interesting is the evidence of ultra sonographic signs of monosodium urate crystalline articulate deposits in $25 \%$ of clinically asymptomatic hyperuricaemic subjects (more than $8 \mathrm{mg}$ / dL) [1], and approximately $9 \%$ of the joints without clinical signs of flogosis [2]. Large epidemiological studies have now demonstrated that gout is an independent risk factor for incident coronary heart disease, [3-6] heart failure, [7] stroke [8] peripheral artery disease [9] and death cardiovascular [10,11]. But, several meta-analyses have concluded that hyperuricaemia is an independent risk factor for coronary heart disease $[12,13]$ and also, for the development of hypertension $[14,15]$. The standard diagnostic goal remains the identification of the typical birefringence of crystals of uric acid under polarized light microscope in the synovial fluid and in the aspirated material from the tophi $[16,17]$. Hyperuricaemia with or without urate deposit (modern denomination of the formerly called gout) is currently one of the most frequent dysmetabolic diseases. $[18,19]$.

Over the last decades, to uric acid has been attributed a possible role of cardiovascular risk prevalently the left ventricular hypertrophy for an increase in inflammatory mediators, such as tumor necrosis factor alpha and activation, and the rennin angiotensin system, increase in interstitial fibrosis of the myocardium and producing endothelial dysfunction [20,21]. Uric acid being a small molecule, is able to penetrate within the vascular wall cells, stimulating inflammatory activity leading to smooth muscle cell hypertrophy and favoring the endothelial dysfunction process [22]. An increase in arterial stiffness has also been demonstrated [23]. The antioxidant effect seems to be attenuated by the increase in its plasma concentration to turn into a pro-oxidant effect when it exceeds the $6 \mathrm{mg} / \mathrm{dL}$ level. In recent years, scientific evidence has suggested the possibility of a pathophysiological correlation between the action of xanthine oxidase and the genesis of cardiovascular damage in patients with chronic hyperuricaemia with and without uric acid deposits [24,25].

\section{Uric Acid}

Uric acid is an organic heterocyclic compound. It is the endproduct of the metabolism of purine nucleotides that are the principal constituents of cellular energy stores, such as ATP, and components of DNA and RNA. Urate ions appear as monosodium urate with a solubility limit in plasma of about $6.8 \mathrm{mg} / \mathrm{dL}$ at $37^{\circ}$. When the crystals precipitate by excessive solute, they are coated with polypeptide or protein molecules [26,27]. Precipitation of uric acid can occur for other factors such as the state of tissue hydration, $\mathrm{pH}$, cation concentrations and the presence of proteoglycans, collagen and chondroitin sulphate. Uric acid is a molecule with an effective antioxidant action (protective: intracellular localization) and a potent pro-oxidant effect (negative impact: extracellular localization) in relation to the micro-environment in which it is located [28]. This dual role has been described as the "uric acid paradox".

\section{Plasma Proteins}

Acid-bearing drugs bind to albumin. Those with basic function are bound to globulins. They are subdivided into three fractions: alpha, beta and gamma. The first two cover transport functions, while the third includes the immuno globulins involved in the body's defense processes.

\section{Synovial fluid}

The synovial fluid under normal conditions is a viscous light yellow and clear. The fluid contains few proteins and cells but is rich in hyaluronic acid (about $300 \mathrm{mg} / \mathrm{dL}$ ) synthesized by type $\mathrm{B}$ synoviocytes which provides high viscosity. The larger molecules, such as immunoglobulin's and complement, are found to be in lower concentrations, made due to the physiological function of the filter. The protein content of normal synovial fluid ranges from $25-30 \%$ of the total plasma protein content, with a very lower proportion of the higher molecular weight proteins such as alpha- 
2-globulin, haptoglobin and fibrinogen (which belongs to beta globulins) because the synovial membrane is impermeable to high molecular weight proteins. Fibrin and fibrinogen are normally not present in synovium. During the inflammatory process an increase of the total proteins is observed as a consequence of the increase of the permeability of the synovial vessels.

\section{Personal Experience}

\section{Cardiovascular}

About three decades ago, working as a general practitioner and cardiologist at the "Dr. Julio Méndez" Municipal Sanatorium (Buenos Aires, Argentina), hyperuricaemia was a factor of concern and discussion about its possible action on the cardiovascular system. We had no doubts about its role in the development of joint gout but we did not have certain data about its action on the arteries. The question was whether hyperuricaemia is an independent risk factor for cardiovascular disease. We knew that the uric acid is transported by very low density lipoproteins which would make them more easily precipitated, prevalently if they find an acid medium inside the arteries. Moreover, the acidity could be caused by the depolymerization of mucopolysaccharides and the presence of bivalent cations would concurrently precipitate the circulating proteins (uric acid carriers), we thought that with the contact of uric acid with chondroitin sulfuric acid of the arteries (similar to the articulate cartilage component), could develop the inflammatory cascade. Hypertension frequently coexists and contributes with hypoxia facilitating the inflammatory action of uric acid and lipoproteins.

Therefore, uric acid would not in itself be a coronary risk factor, but would act in combination with hypertension, hyperlipidaemia and/or hyperglycaemia. During the time I drove of the Ischemic Heart Disease team, in order to know the relationship between hyperuricaemia and cardiovascular disease, 40 patients both gender was enrolled with ischemic heart disease studied with electrocardiogram, cycloergometry, echocardiogram and coronary angiography. The male group (35) had a mean age of 56 years, with a history of myocardial infarction [27] and myocardial ischemia [8], and in the female group (5) had a mean age of 64 years only with myocardial ischemia. All patients had a hyperuricaemia $10 \%$ higher than normal level for each gender. Only one patient had hyperuricaemia, the rest of the sample had two or more cardiovascular risk factors: high blood pressure (55\%), hereditary history of cardiovascular disease (50\%), smoking (43\%), Obesity (38\%), hyperlipidaemia IIa (38\%), hyperlipidaemia IV (38\%), diabetes mellitus (30\%), gout (39\%), and sedentarism (18\%).

\section{Conclusion}

Apparently hyperuricaemia alone not be a risk factor but, in combination with hypertension, hyperlipidaemia and/or hyperglycaemia, could develop the inflammatory cascade acting on the endothelium. No woman had myocardial infarction or articulate gout. The level of uricaemia was not related to the severity of cardiovascular disease. Interestingly, the group older than 60 years with hyperuricaemia had greater risk. Hyperuricaemia, hypertension, hyperlipidaemia and age greater than 60 years in males would be associated with a higher severity of cardiovascular risk, and would favor the development of atherosclerosis [29].

\section{Joints}

There were also several doubts about the development of joint gout in patients with serum acid levels below $7 \mathrm{mg} / \mathrm{dL}$, and why the lack of clinical symptomatology in other patients with severe reduced glomerular filtration rate with exceptional levels of uricaemia such as $17 \mathrm{mg} / \mathrm{dL}$. Monosodium urate is deposited only if the medium is acid as occurs in the urine, and in contact with the chondroitin sulfuric acid in the joints. A possibility of producing a gouty acute attack with non-high levels of uricaemia could indicate that the uric acid introduced into the joint would not have an element that would function as a shock absorber. In the same line of thought, it was possible to arrive at the conjecture that during the acute inflammation, and for the benefit of the local vasodilatation, there could be a passage of elements that had a damping action. The question was: What are the elements that are not found in large quantities in normal synovial fluid and increase during inflammation? It was first thought of the higher molecular weight plasma proteins as the alpha and beta globulins as well as fibrinogen. An investigation was carried out in order to clarify these doubts It was decided to take samples of the synovial fluid of the knee from gouty (20) and non-gouty (20) patients. Hyaluronidase to synovial fluid was added in order to decrease its own viscosity. Once liquefied, a sample was taken to perform a protein electrophoresis. Technically it was not possible to measure fibrinogen intraarticulate. The next step was to compare the amounts of alpha, beta, and gamma proteins of the two patient groups. It was observed that in patients with acute joint gout fractions of alpha and beta globulins were always significantly lower than those of health patients. (Unpublished data) We hypothesized that patients with less alpha and beta globulins in the synovial liquid were more sensitive to developing joint gout.

\section{Conclusion}

The acute attack of gout, without a high uric acid level, could be caused by the low presence of high molecular weight proteins in the synovial fluid. If the disease is heritable, the reduction of alpha and beta proteins could be inherited. The self-limitation of the gouty attack could occur by the entry of proteins of high molecular weight, secondary to the vasodilatation produced by the acute inflammation, which would function as buffer. Other proteins and/ or substances could also be buffers such as fibrinogen.

\section{References}

1. Pineda C, Amezcua Guerra LM, Solano C, Rodriguez Henriquez P, Hernandez Diaz C, et al. (2011) Joint and tendon subclinical involvement suggestive of gouty arthritis in asymptomatic hyperuricemia: an ultrasound controlled study. Arthritis Research \& Therapy 13(1): R4. 
2. Filippucci E, Scirè CA, Delle Sedie A, Iagnocco A, Riente L, et al. (2010) Ultrasound imaging for the rheumatologist. XXV. Sonographic assessment of the knee in patients with gout and calcium pyrophosphate deposition disease. Clin Exp Rheumatol 28(1): 2-5.

3. Abbott RD, Brand FN, Kannel WB, Castelli WP (1988) Gout and coronary heart disease: the Framingham Study. J Clin Epidemiol 41(3): 237-242.

4. Krishnan E, Baker JF, Furst DE, Schumacher HR (2006) Gout and the risk of acute myocardial infarction. Arthritis rheum 54(8): 2688-2696.

5. Choi HK, Curhan G (2007) Independent impact of gout on mortality and risk for coronary heart disease. Circulation 116(8): 894-900.

6. De Vera MA, Rahman MM, Bhole V, Kopec JA, Choi HK (2010) Independent impact of gout on the risk of acute myocardial infarction among elderly women: a population-based study. Ann Rheum Dis 69(6): 1162-1164.

7. Krishnan E (2012) Gout and the risk for incident heart failure and systolic dysfunction. BMJ Open 2(1): e000282.

8. Seminog 00, Goldacre MJ (2013) Gout as a risk factor for myocardial infarction and stroke in England: evidence from record linkage studies. Rheumatology (Oxford) 52(12): 2251-2259.

9. Baker JF, Schumacher HR, Krishnan E (2007) Serum uric acid level and risk for peripheral arterial disease analysis of data from the multiple risk factor intervention trial. Angiology 58(4): 450-457.

10. Lottmann K, Chen X, Schadlich PK (2012) Association between gout and all-causes as well as cardiovascular mortality a systematic review. Curr Rheumatol Rep 14(2): 195-203.

11. Teng GG (2012) Mortality due to coronary heart disease and kidney disease among middle-aged and elderly men and women with gout in the Singapore Chinese Health Study. Ann Rheum Dis 71: 924-928.

12. Kim SY, Guevara JP, Kim KM, Choi HK, Heitjan DF, et al. (2010) Hyperuricemia and coronary heart disease: a systematic review and meta analysis. Arthritis Care Res (Hoboken) 62(2): 170-180.

13. Kim SY, Guevara JP, Kim KM, Choi HK, Heitjan DF, et al. (2009) Hyperuricemia and risk of stroke: a systematic review and meta analysis. Arthritis Rheum 61(7): 885-892.

14. Grayson PC, Kim SY, LaValley M, Choi HK (2010) Hyperuricemia and incident hypertension: a systematic review and meta-analysis. Arthritis Care Res (Hoboken) 63(1): 102-110.

15. Zhang W, Sun K, Yang Y, Zhang H, Hu FB, et al. (2009) Plasma uric acid and hypertension in a Chinese community: prospective study and metaanalysis. Clin Chem 55(11): 2026-2034.

16. Zhang W, Doherty M, Pascual E, Bardin T, Barskova V, et al. (2006) EULAR evidence based recommendations for gout. Part I: Diagnosis. Report of a task force of the standing committee for international clinical studies including therapeutics (ESCISIT). Ann Rheum Dis 65(10): 1301-1311.
17. Manara M, Bortoluzzi A, Favero M, Prevete I, Scirè CA, et al. (2013) Italian Society of Rheumatology recommendations for the management of gout. Reumatismo 65(1): 4-21.

18. Wallace KL, Riedel AA, Joseph Ridge N, Wortmann R (2004) Increasing prevalence of gout and hyperuricemia over 10 years among older adults in a managed care population. J Rheumatol 31(8): 1582-1587.

19. Roddy E, Doherty M (2010) Epidemiology of gout. Arthritis Res Therapy 12: 223 .

20. Corry DB, Eslami P, Yamamoto K, Tuck ML (2008) Uric acid stimulates vascular smooth muscle cell proliferation and oxidative stress via the vascular renin-angiotensin system. J Hypertens 26: 269-275.

21. Yu MA, Sanchez Lozada LG, Johnson RJ, Kang DH (2010) Oxidative stress with an activation of the renin-angiotensin system in human vascular endothelial cells as a novel mechanism of uric acid induced endothelial dysfunction. J Hypertens 28(6): 1234-1242.

22. Ferrucci L, Corsi A, Lauretani F, Stefania Bandinelli, Benedetta Bartali,et al. (2005) The origins of age-related proinflammatory state. Blood 105(6): 2294-2299.

23. Vlachopoulos C, Xaplanteris P, Vyssoulis G (2011) Association of serum uric acid level with aortic stiffness and arterial wave reflections in newly diagnosed, never treated hypertension. Am J Hypertens 24(1): 33-39.

24. Grassi D, Desideri G, Ferri C (2014) New Insight into Urate-Related Mechanism of Cardiovascular Damage. Curr Pharm Des 20(39): 60896095.

25. Tam HK, Kelly AS, Metzig AM, Steinberger J, Johnson LA (2014) Xanthine oxidase and cardiovascular risk in obese children. Child Obes 10(2): 175-180.

26. Richette P, Bardin T (2010) Gout Lancet 375(9711): 318-328.

27. (2012) Considerations on gotta, uric acid and cardiovascular risk. Evidences of controversial aspects and future perspectives CRISTAL. Synergies Scientific Editions.

28. So A, Thorens B (2010) Uric acid transport and disease. J Clin Invest $120(6): 1791-1799$.

29. (1980) Hyperuricaemia as a determining co-factor of coronary arteriopathy. Presented at the II Annual Clinical Surgical Meeting. The Committee of Teaching and Investigation of the Municipal Sanatorium (Buenos Aires - Argentina) accredited for the Medicine branch award "Dr. Pedro Ferrario".

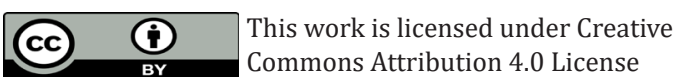

To Submit Your Article Click Here:

Submit Article

DOI: 10.32474/ACR.2018.01.000103

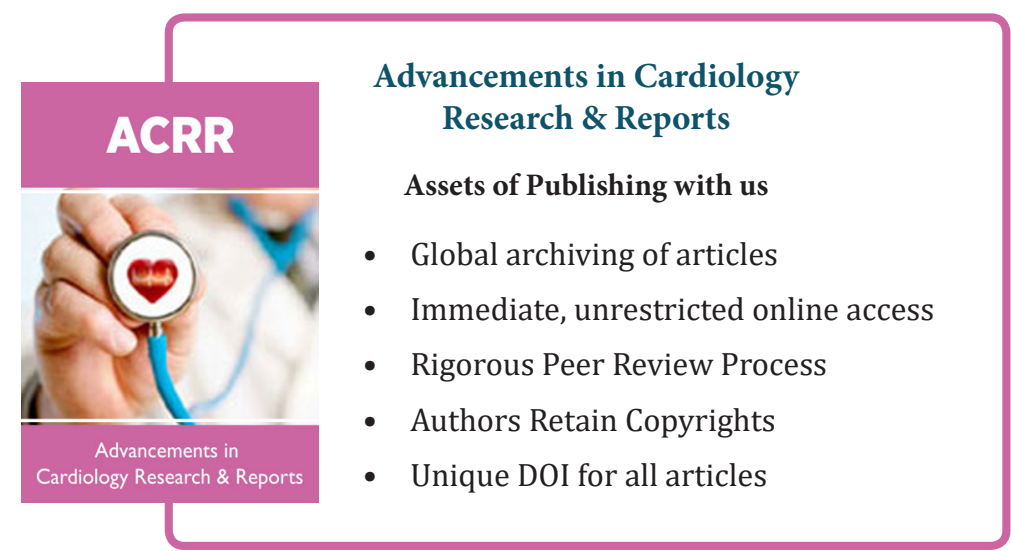

